\title{
PENGARUH KEPERCAYAAN DAN KOMITMEN TERHADAP KEPUASAN SUPPLIER BERAS DI PERUSAHAAN UMUM BADAN URUSAN LOGISTIK (Studi Kasus : Di Perum BULOG Kantor Cabang Cianjur)
}

\author{
Oleh : \\ Yola Nurkamil*) \\ Asep Saepul Alam*) \\ Siti Nursilah**)
}

\begin{abstract}
Abstrak
Beras merupakan komoditas pangan utama masyarakat Indonesia, Perum BULOG yang mempunyai tugas pokok mengelolaan persediaan, khususnya beras bermitra dengan petani, Gapoktan, dan pabrik beras sebagai supplier. Supplier memiliki peran yang sangat besar bagi Perum BULOG dalam proses pengadaan beras. Keberhasilan hubungan kerja sama antara perusahaan dan supplier dapat dilihat dari kinerja yang diukur dengan tingkat kepuasan melalui rasa saling percaya dan menjaga komitmen kerja sama. Tujuan penelitian ini yaitu untuk mengetahui pengaruh secara parsial kepercayaan dan komitmen terhadap kepuasan supplier, dan untuk mengetahui pengaruh secara simultan kepercayaan dan komitmen terhadap kepuasan supplier di Perum BULOG. Penelitian ini menggunakan data primer dan data sekunder. Data primer diperoleh dari wawancara dan pengisian kuesionerke 30 responden. Data sekunder diperoleh dari skripsi terdahulu, tesis, buku, dan internet. Metode analisis yang digunakan yaitu metode analisis deskripsif kuantitatif menggunakan analisis regresi linier berganda dengan bantuan software IBM SPSS 25. Hasil dari penelitian ini menunjukkan bahwa (1) kepercayaan berpengaruh nyata secara parsial terhadap kepuasan supplier, karena memiliki nilai t hitung $>\mathrm{t}$ table yaitu sebesar 2,532 $>2,051$, memiliki nilai signifikansi $0,017<0,05$, (2) komitmen berpengaruh nyata secara parsial terhadap kepuasan supplier, karena memiliki nilai $\mathrm{t}$ hitung $>\mathrm{t}$ table yaitu sebesar 3,313 > 2,051, memiliki nilai signifikansi $0,003<0,05$, (3) kepercayaan dan komitmen berpengaruh secara simultan terhadap kepuasan supplier, karena memiliki nilai $\mathrm{f}$ hitung $>\mathrm{f}$ table yaitu $9.202>3,34$ dengan tingkat signifikansi $<0,05$ yaitu 0,001. Kepercayaan dan komitmen memiliki kontribusi sebesar 40,5\% terhadap kepuasan supplier.
\end{abstract}

Kata kunci: Kepercayaan, Komitmen, Kepuasan supplier.

\begin{abstract}
Rice is the main food commodity of Indonesian society, Perum BULOG which has the main task of managing supplies, especially rice in partnership with farmers, Gapoktan, and rice factories as suppliers. Suppliers have a very big role for Perum BULOG in the rice procurement process. The success of the cooperative relationship between the company and the supplier can be seen from the performance as measured by the level of satisfaction through mutual trust and maintaining cooperation commitment. The purpose of this study is to determine the partial effect of trust and commitment on supplier satisfaction, and to determine the effect of trust and commitment simultaneously on supplier satisfaction at Perum BULOG. This study uses primary data and secondary data. Primary data obtained from interviews and filling out questionnaires to 30 respondents. Secondary data were obtained from previous theses, theses, books, and the internet. The
\end{abstract}

\begin{tabular}{lrrr}
\hline PENGARUH & KEPERCAYAAN & DAN & YOLA NURKAMIL, ASEP SAEPUL ALAM \\
KOMITMEN & TERHADAP KEPUASAN & dan SITI NURSILAH
\end{tabular}


analytical method used is descriptive quantitative analysis method using multiple linear regression analysis with the help of IBM SPSS 25 software. The results of this study indicate that (1) trust has a partially significant effect on supplier satisfaction, because it has a value of $t$ count $>t$ table, which is $2.532>2,051$, has a significance value of $0.017<0.05$, (2) commitment has a partially significant effect on supplier satisfaction, because it has a value of $t$ count $>t$ table which is 3,313> 2,051, has a significance value of $0.003<0.05$, (3) Trust and commitment have a simultaneous effect on supplier satisfaction, because it has a value of $f$ count $>f$ table, namely 9,202> 3.34 with a significance level of $<0.05$, namely 0.001. Trust and commitment contributed $40.5 \%$ to supplier satisfaction.

Keywords: Trust, Commitment, Supplier satisfaction.

*) Dosen Fakultas Sains Terapan UNSUR.

**) Alumni Fakultas Sains Terapan UNSUR. 


\section{PENDAHULUAN}

Beras merupakan komoditas pangan utama masyarakat Indonesia, setiap harinya hampir seluruh penduduk di Indonesia mengkonsumsi beras. (Bulog, 2018). Hal ini menyebabkan komoditas beras memiliki nilai yang sangat strategis, selain itu, beras juga berperan besar dalam sebagian besar rakyat Indonesia. (Rachman dan Mohamad, 2010).

Menurut Yuniarti dan Mudya (2016) konsumsi beras di Indonesia pada tahun 2015 mencapai 22,285 juta ton dan pada tahun 2016 konsumsi beras nasional diperkirakan mencapai 22,57 juta ton atau meningkat $1,27 \%$ dibandingkan tahun 2015. Pada tahun 2017 konsumsi beras diperkirakan meningkat $1,23 \%$ dari tahun 2016 menjadi 22,85 juta ton. Peningkatan tersebut dikarenakan beras sebagai bahan konsumsi dipengaruhi oleh beberapa faktor salah satunya yaitu jumlah penduduk. Oleh karena itu, semakin banyak jumlah penduduk, maka semakin tinggi pula konsumsi beras. Sejalan dengan pertambahan penduduk dan juga peningkatan konsumsi beras perkapita menyebabkan persediaan beras dihadapkan pada posisi rawan karena terjadinya alih fungsi lahan sebagai akibat dari tuntutan pembangunan. (Etiyati, 2011 dalam Bella, 2019).

Hal tersebut merupakan tantangan nyata bagi negara untuk terus menjaga stabilitas pangan khususnya ketersediaan beras. Stabilitas pangan berasal dari permasalahan-permasalahan didunia yang mendasar dan menentukan nasib dari suatu Negara. Pangan sendiri merupakan sesuatu kebutuhan bagi manusia yang sangat penting untuk keberlangsungan hidup karena pangan sangat penting pengaruhnya menyangkut tentang tingkat kemakmuran rakyat di Negara tersebut. (Reza,2017).

Badan Urusan Logistik (BULOG) yang dibentuk pada tanggal 10 Mei 1967 melalui Peraturan Pemerintah RI No. 7 tahun 2003, BULOG beralih status menjadi Perusahaan Umum (Perum)
BULOG yang mempunyai tugas pokok yaitu melaksanakan tugas pemerintah di bidang manajemen logistik melalui pengelolaan persediaan, distribusi dan pengendalian harga beras dengan tetap mempertahankan Harga Pembelian Pemerintah (HPP) sesuai dengan peraturan perundang-undangan yang berlaku. (Bulog, 2018). Dalam menjalankan tugas pokok tersebut Perum BULOG bermitra dengan petani, Gapoktan, dan pabrik beras sebagai supplier. Menurut Nadja dkk, (2018) tidak bisa dipungkiri bahwa supplier memiliki peran yang sangat besar bagi Perum BULOG, hal tersebut dikarenakan proses pengadaan salah satu produk Perum BULOG yaitu beras berawal dari supplier melalui mitra kerja yang bekerja sama dengan BULOG.

Perum BULOG Kantor Cabang Cianjur yang bertugas mengurus penyaluran pada tiap-tiap daerah dan bertanggung jawab melaporkan segala aktivitas yang terdapat di Kantor Cabang kepada Kantor Pusat. Untuk memperlancar proses pengadaan gabah/beras di Perum BULOG terdapat faktor-faktor yang mempengaruhi pengadaan, salah satunya yaitu kepuasaan yang diterima oleh supplier dari perusahaan. Selain itu, Menurut Fiero dan Redondo dalam Filiani (2009) menyatakan bahwa yang menjadi sumber daya saing yang tinggi di perusahaan salah satunya yaitu pengelolaan hubungan yang baik dengan cukup supplier. Keberhasilan hubungan yang baik dapat dilihat dari kinerja yang diukur dari tingkat kepuasan.

Agar terciptanya hubungan yang baik antara perusahaan maupun supplier, kedua belah pihak harus saling percaya dan juga harus saling terbuka satu sama lain terlebih lagi informasi-informasi yang dapat berpengaruh terhadap perencanaan kerjasama kedepannya. Dengan adanya kepercayaan yang terjalin antara perusahaan dan supplier, kepercayaan tersebut dapat dijadikan instrument penting bagi peningkatan kepuasan supplier. (Filiani, 2009). 
Selain kepercayaan, komitmen juga menjadi faktor yang dapat mempengaruhi kepuasan supplier. Menurut Jasfar (2005) dalam Nurvalentien (2014) menyatakan bahwa komitmen adalah rasa saling percaya dan mempercayai diantara pihakpihak yang menjalin hubungan bisnis, baik secara tersirat (implicit) maupun tidak tersirat (explicit) bahwa hubungan bisnis mereka akan berlangsung secara terus menerus dan masing-masing pihak menjaga agar janji diantara pihak satu dengan pihak yang lainnya terpelihara. Hal tersebut sejalan dengan Ariani (2013) dimana hubungan supplier (pemasok) dengan produsen harus sehat dan dipelihara, karena tingkat ketergantungan perusahaan terhadap supplier sangat tinggi dan bersifat jangka panjang.

Berdasarkan latar belakang diatas, penulis tertarik untuk melakukan penelitian mengenai kepuasan supplier yang ada di Perum BULOG yang akan dituangkan dalam penelitian berjudul "Pengaruh Kepercayaan dan Komitmen Terhadap Kepuasan Supplier Beras Di Perusahaan Umum Badan Urusan Logistik (Studi Kasus : Di Perum BULOG Kantor Cabang Cianjur)".

\section{METODE PENELITIAN}

Penelitian ini dilakukan di Perum BULOG Kantor Cabang Cianjur yang beralamat di Jl. DR. Muwardi No. 175 A, Bojong herang, Kec. Cianjur, Kabupaten Cianjur, Jawa Barat 43216, di mulai dari bulan Desember 2019 sampai dengan bulan Agustus 2020.

Penelitian ini menggunakan data primer dan data sekunder. Data primer diperoleh dari wawancara dan pengisian kuesioner. Data sekunderdiperolehdariskripsiterdahulu, tesis, buku, dan internet. Teknik pengumpulan data yang digunakan yaitu observasi, wawancara, kuesioner dan dokumentasi.

Variabel dalam penelitian ini yaitu Variabel independen (X) penelitian ini yaitu kepercayaan dan komitmen, sedangkan untuk variable dependen $(\mathrm{Y})$ yaitu kepuasan supplier.

Populasi dalam penelitian ini yaitu petani, Gabungan Kelompok Tani, dan juga pabrik beras yang merupakan supplier beras atau mitra kerja dari Perum BULOG Kantor Cabang Cianjur yang tidak diketahui berapa jumlahnya.

Teknik pengambilan sampel yang digunakan yaitu Non probability sampling, dalam penelitian ini jumlah responden yang dijadikan sampel yaitu sebanyak 30 orang atau responden. Dalam menentukan pengambilan responden digunakan teknik Insidental Sampling.

Metode analisis yang digunakan yaitu metode analisis deskripsif kuantitatif menggunakan analisis regresi linier berganda dengan bantuan software IBM SPSS 25 dengan tahapan :

1. Uji Validitas

2. Uji Reliabilitas

3. AnalisisRegresi Linier Berganda

4. Uji t (Uji Secara Parsial)

5. Uji F (Uji KoefisienSimultan)

6. AnalisisDeterminasi (R2)

\section{HASIL DAN PEMBAHASAN}

Perusahaan Umum Badan Urusan Logistik (Perum BULOG) Sub Divisi Regional (Sub Divre) Cianjur merupakan salah satu dari 132 Sub Divre yang tersebar hampir di seluruh kabupaten di Indonesia. Perum BULOG Sub Divre Cianjur didirikan serentak dengan berdirinya BULOG di Indonesia yaitu pada tanggal 10 Mei 1967 dan pada 2019 Sub Divre Cianjur berubah nama menjadi kantor cabang dan pada tahun 2020 kantor cabang mulai efektif menggunakan nama Perum BULOG Kantor Cabang Cianjur, saat ini Perum BULOG Kantor Cabang Cianjur dikepalai oleh Bapak Agus Siswantoro dengan membawahi 3 Kota, yaitu : Kota Sukabumi, Kota Bogor, dan Kota Depok, serta membawahi 3 Kabupaten, yaitu : Kabupaten Cianjur, Kabupaten Bogor, dan Kabupaten Sukabumi.

Visi dan Misi Perum Bulog Kantor Cabang Cianjur : 
Visi

"Menjadi perusahaan yang unggul dan terpercaya dalam mendukung terwujudnya kedaulatan pangan".

\section{Misi}

1. Menjalankan usaha logistic pangan pokok dengan mengutamakan layanan kepada masyarakat.

2. Melaksanakan praktik manajemen unggul dengan dukungan sumber daya manusia yang profesional, teknologi yang terdepan dan sistem yang terintegrasi.

3. Menerapkan prinsip tata kelola perusahaan yang baik serta senantiasa melakukan perbaikan yang berkelanjutan.

4. Menjamin ketersediaan, dan stabilitas komoditas pangan pokok, dan keterjangkauan.

\section{Uji Validitas}

Rumus Uji validitas dengan koefisien $5 \%$ yaitu df $=\mathrm{n}-\mathrm{k}$ (Ghozali, 2011) Dengan degree of freedom (df) $=$ (n - 2) yaitu sampel berjumlah 30 responden (n) $-2=28$ dan alpha $(\alpha) 0,05$, maka didapat $r$ table sebesar 0,361 . Berikut ini hasil uji validitas dari masingmasing variabel :

Tabel 1. Hasil Uji Validitas Variabel Kepercayaan (X1).

\begin{tabular}{cccc}
\hline Nomor Item & r Hitung & r Tabel $\mathbf{5 \%} \mathbf{( 1 0 0 )}$ & Keterangan \\
\hline 1 & 0,400 & 0,361 & Valid \\
2 & 0,521 & 0,361 & Valid \\
3 & 0,563 & 0,361 & Valid \\
4 & 0,466 & 0,361 & Valid \\
5 & 0,371 & 0.361 & Valid \\
6 & 0,365 & 0,361 & Valid \\
7 & 0,397 & 0,361 & Valid \\
8 & 0,373 & 0,361 & Valid \\
9 & 0,432 & 0,361 & Valid \\
10 & 0,531 & 0,361 & Valid \\
11 & 0,493 & 0,361 & Valid \\
12 & 0,506 & 0,361 & Valid \\
\hline
\end{tabular}

Sumber: Data Primer (Diolah, 2020).

Dari tabel 1. untuk variable kepercayaan (X1) yang dibagi menjadi 4 bagian dengan total 12 item dinyatakan valid karena seluruh item pernyataan dengan alpha $(\alpha) \quad 5 \% \quad(0,05)$ tersebut memiliki nilai yang lebih besar dari hasil $r$ tabel (0,361). Dari hasil uji validitas tersebut item nomor 3 memiliki nilai tertinggi yaitu 0,563, item tersebut mengenai "Perum BULOG berdiskusi dengan supplier untuk meningkaatkan kualitas produk". Berdasarkan hasil wawancara dilapangan, hal tersebut dilakukan perusahaan agar produka tau beras yang dikirim oleh supplier sudah memenuhi persyaratan penerimaan beras perusahaan. 
Tabel 2.Hasil Uji Validitas Variabel Komitmen (X2).

\begin{tabular}{cccc}
\hline Nomor Item & r Hitung & r Tabel $\mathbf{5 \%}(\mathbf{1 0 0})$ & Keterangan \\
\hline 1 & 0,394 & 0,361 & Valid \\
2 & 0,383 & 0,361 & Valid \\
3 & 0,488 & 0,361 & Valid \\
4 & 0,366 & 0,361 & Valid \\
5 & 0,362 & 0.361 & Valid \\
6 & 0,375 & 0,361 & Valid \\
7 & 0,678 & 0,361 & Valid \\
8 & 0,385 & 0,361 & Valid \\
9 & 0,370 & 0,361 & Valid \\
\hline
\end{tabular}

Sumber: Data Primer (Diolah, 2020).

Dari tabel 2. Untuk variable komitmen (X2) yang dibagi menjadi 3 bagian dengan total 9 item dinyatakan valid karena seluruh item pernyataan dengan alpha $(\alpha) \quad 5 \% \quad(0,05)$ tersebut memiliki nilai yang lebih besar dari hasil $\mathrm{r}$ tabel (0,361). Dari hasil uji validitas tersebut item nomor 7 memiliki nilai tertinggi yaitu 0,678 , item tersebut mengenai "Perum BULOG selalu menepati perjanjian kerja sama", hal tersebut terjadi karena dengan Perum BULOG selalu menepati perjanjian kerja sama akan membuat supplier percaya untuk melakukan kerja sama yang berkelanjutan.

Tabel 3. Hasil Uji ValiditasVariabelKepuasan Supplier (Y).

\begin{tabular}{cccc}
\hline Nomor Item & $\mathbf{r}$ Hitung & $\mathbf{r}$ Tabel $\mathbf{5 \%} \mathbf{( 1 0 0 )}$ & Keterangan \\
\hline 1 & 0,385 & 0,361 & Valid \\
2 & 0,653 & 0,361 & Valid \\
3 & 0,395 & 0,361 & Valid \\
4 & 0,544 & 0,361 & Valid \\
5 & 0,479 & 0.361 & Valid \\
6 & 0,381 & 0,361 & Valid \\
7 & 0,368 & 0,361 & Valid \\
8 & 0,420 & 0,361 & Valid \\
9 & 0,497 & 0,361 & Valid \\
10 & 0,451 & 0,361 & Valid \\
11 & 0,368 & 0,361 & Valid \\
12 & 0,803 & 0,361 & Valid \\
\hline
\end{tabular}

Sumber: Data Primer (Diolah, 2020).

Dari tabel 3. untuk variable kepuasan supplier (Y) yang dibagi menjadi 4 bagian dengan total 12 item dinyatakan valid karena seluruh item pernyataan dengan alpha $(\alpha) \quad 5 \% \quad(0,05)$ tersebut memiliki nilai yang lebih besar dari hasil $r$ tabel (0,361). Dari hasil uji validitas tersebut item nomor memiliki nilai tertinggi yaitu 0,803, item tersebut mengenai "Perum BULOG menampung semua jenis beras". Berdasarkan hasil di lapangan, reponden yang berstatus sebagai supplier tetap berpendapat bahwa perusahaan menerima semua jenis beras dari supplier selagi beras tersebut memenuhi persyaratan dari perusahaan, namun untuk jenis beras khusus perusahaan hanya menerimanya pada waktu-waktu tertentu saja. 
Uji Reliabilitas

Uji reliabilitas dilakukan untuk mengetahui bahwa indikator (instrument) yang digunakan dapat dipercaya atau dapat diandalkan.

Tabel 4.Hasil Uji Reliabilitas.

\begin{tabular}{clccc}
\hline \multicolumn{5}{c}{ Reliability Statistics } \\
\hline No & \multicolumn{1}{c}{ Variabel } & Cronbach's Alpha & N of Items & Ket \\
\hline 1. & Kepercayaan (X1) & 629 & 12 & Reliabel \\
2. & Komitmen (X2) & 664 & 9 & Reliabel \\
3. & KepuasanSupplier $(\mathrm{Y})$ & 631 & 12 & Reliabel
\end{tabular}

Sumber: Data Primer (Diolah, 2020).

Hasil pengujian Reliability Statistics tersebut, diketahui jumlah item ( $\mathrm{N}$ of item) yang diteliti pada variabel kepercayaan (X1) berjumlah 12 item dengan diperoleh nilai Cronbach's Alpha sebesar 0,629, sedangkan variabel komitmen (X2) dengan jumlah 9 item memperoleh Cronbach's Alpha sebesar 0,664, dan untuk variabel kepuasan supplier (Y) dengan jumlah 12 item memperoleh Cronbach's Alpha sebesar 0,631. Berdasarkan nilai reliabilitas tersebut dapat disimpulkan bahwa semua kuesioner dalam penelitian ini reliabel atau konsisten karena memiliki nilai Cronbach's Alpha lebih besar dari 0.60, sehingga kuesioner tersebut dapat digunakan sebagai instrumen untuk penelitian dan jawaban dari 30 responden terhadap pernyataan - pernyataan yang digunakan untuk mengukur variabel kepercayaan (X1), variabel komitmen
(X2), dan variabel kepuasan supplier (Y) adalah konsisten atau dapat dipercaya (reliabel).

Dari hasil uraian diatas, variabel komitmen (X2) memiliki nilai tertinggi yaitu sebesar 0,664, hal ini menunjukkan bahwa variabel komitmen (X2) lebih konsisten dari variabel lainnya. Hal ini sejalan dengan penelitian Ariani (2013) yang berpendapat bahwa hubungan supplier atau pemasok dengan produsen harus sehat dan terpelihara, karena tingkat ketergantungan perusahaan terhadap supplier sangat tinggi dan bersifat jangka panjang.

\section{AnalisisRegresi Linier Berganda}

Analisis regresi linier berganda dilakukan untuk mengetahui ada tidaknya pengaruh dua variable bebas $(\mathrm{X})$ terhadap variable terikat (Y). (Sugiyono, 2016).

Tabel 5. Hasil analisis Regresi Berganda Coefficientsa.

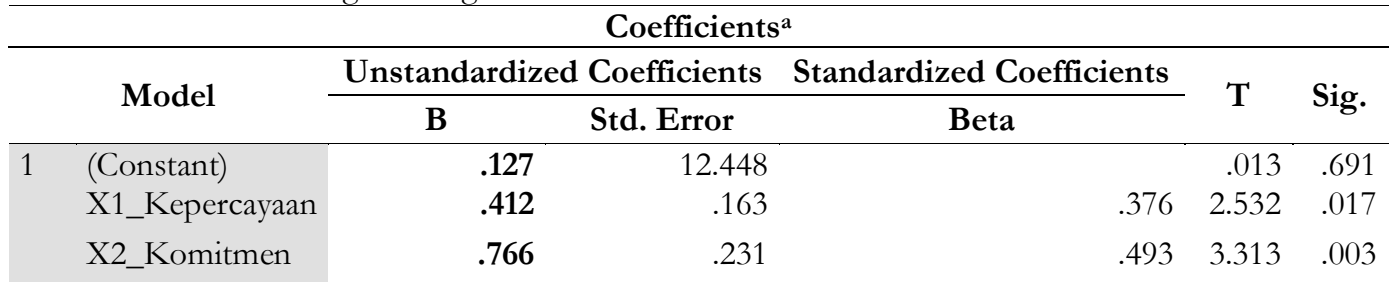

a. Dependent Variabel: Kepuasan

Sumber: Data Primer Diolah (2020).

Berdasarkan tabel 5. Maka dapat dirumuskan persamaan regresi linier berganda sebagai berikut :

$$
\mathrm{Y}=\mathrm{a}+\mathrm{b} 1 \mathrm{X} 1+\mathrm{b} 2 \mathrm{X} 2+\mathrm{e}
$$

Keterangan :

$\mathrm{Y}=$ Kepuasan supplier

$\mathrm{a}=$ Konstanta b1 = Koefisien Kepercayaan

b2 = Koefisien Komitmen

$\mathrm{X} 1=$ Variabel Kepercayaan

$\mathrm{X} 2=$ VAriabel Komitmen

Kepuasan Supplier $=$ $0,127+0,412 \times 1+0,766 \times 2+e$ 
Berdasarkan persamaan regresi di atas, maka dapat diketahui bahwa :

1. Hasil nilai koefisien konstan ta menunjuk kanangka sebesar 0,127 . Hal tersebut berarti bahwa rata-rata variabel kepuasan supplier $(\mathrm{Y})$ akan mengalami penurunan sebesar 0,127 atau $12,7 \%$ apabila variable kepercayaan (X1) dan variable komitmen (X2) sama dengan nol (0).

2. Hasil regresi variable kepercayaan (X1) sebesar 0,412. Dari hasil tersebut dapat diartikan bahwa jika kepercayaan mengalami peningkatan atau kenaikan sebesar 1\% maka akan meningkatkan kepuasan supplier sebesar $41,2 \%$ dengan asumsi variable independen lainnya tetap. Semakin baik perusahaan menjaga kepercayaan maka akan semakin meningkat juga kepuasan supplier.

3. Hasil regresi variabel komitmen (X2) sebesar 0,766. Dari hasil tersebut dapat diartikan bahwa jika komitmen mengalami peningkatan atau kenaikan sebesar 1\% maka akan meningkatkan kepuasan supplier sebesar 76,6\% dengan asumsi variable laiinnya tetap. Semakin baik komitmen yang dijaga perusahaan maka akan semakin meningkat juga kepuasan supplier.

4. Hasil Uji t (Uji Koefisien Regresi Secara Parsial) dasar pengambilan keputusan dalam uji t yaitu berdasakan nilai signifikansi dan juga berdasarkan perbandingan $t$ hitung dengan $t$ tabel, jika nilai signifikansi $<0,05$ dan $\mathrm{t}$ hitung $>\mathrm{t}$ tabel, maka variabel $\mathrm{X}$ secara parsial berpengaruh terhadap variabel Y. Jika signifikansi $>0,05$ dan $\mathrm{t}$ hitung $<\mathrm{t}$ tabel, maka variabel $\mathrm{X}$ tidak berpengaruh secara parsial terhadap variabel Y. Adapun rumus untuk mencari $\mathrm{t}$ table sebagai berikut :

$\mathrm{t}$ tabel $=\mathrm{t}(\mathrm{a} / 2):(\mathrm{n}-\mathrm{k}-1)=\mathrm{t}$

$$
\begin{aligned}
& =(0,05 / 2:(30-2-1) \\
& =0,025: 27
\end{aligned}
$$

$\mathrm{t}$ tabel $=2,051$

Keterangan :

$\mathrm{a}=$ tingkat kepercayaan / koefisien

$\mathrm{n}=$ jumlah sampel

$\mathrm{k}=$ jumlah variabel $\mathrm{X}$

\begin{tabular}{|c|c|c|c|c|c|c|c|}
\hline \multicolumn{8}{|c|}{ Coefficients $^{a}$} \\
\hline & \multirow{2}{*}{ Model } & \multicolumn{2}{|c|}{ Unstandardized Coefficients } & \multicolumn{2}{|c|}{ Standardized Coefficients } & \multirow[b]{2}{*}{$\mathbf{T}$} & \multirow[b]{2}{*}{ Sig. } \\
\hline & & B & Std. Error & Beta & & & \\
\hline \multirow[t]{3}{*}{1} & (Constant) & .127 & 12.448 & & & .013 & .619 \\
\hline & $\begin{array}{l}\text { X1_Kepercayaa } \\
\text { n }\end{array}$ & .412 & .163 & & .376 & 2.532 & .017 \\
\hline & X2_Komitmen & .766 & .231 & & .493 & 3.313 & .003 \\
\hline
\end{tabular}

Tabel 6. Hasil Uji t.

a.Dependent Variable: Kepuasan.

Sumber : Data Primer (Diolah, 2020).

Berdasarkan tabel 6 pengaruh dari variabel $\mathrm{X}$ terhadap variabel $\mathrm{Y}$ sebagai berikut :

\section{1) Pengaruh Kepercayaan terhadap Kepuasan Supplier (Y)}

Berdasarkan table diatas, diperoleh bahwa nilai t hitung $>\mathrm{t}$ table yaitu 2,532 $>2.051$, dan memiliki nilai signifikansi $0,017<0,05$. Dengan demikian ada pengaruh nyata (signifikan) secara parsial dari variabel kepercayaan (X1) terhadap kepuasan supplier (Y), maka dapat diartikan bahwa hipotesis $\mathrm{H} 1$ diterima dan H0 ditolak. Hal ini menunjukkan bahwa supplier sangat puas dengan apa yang diberikan oleh perusahaan. Hal tersebut terlihat dari jawaban responden yang sebagian besar responden memberikan jawaban sangat baik (SB) untuk variable kepercayaan (X1), seperti item "Perum BULOG memberikan pelayanan yang baik kepada supplier" memiliki persentase $70 \%$, item "Perum BULOG bertanggungjawab dalam kerjasama" dan item "Perum BULOG juga memberikan informasi yang dibutuhkan oleh supplier" memiliki persentase masing - masing $63 \%$. Informasi yang dibutuhkan supplier 
tersebut yaitu informasi mengenai naik turunnya harga beras.

\section{2) Pengaruh Komitmen (X2) terhadap Kepuasan Supplier (Y)}

Berdasarkan table di atas, diperoleh bahwa nilai $\mathrm{t}$ hitung $>\mathrm{t}$ tabelyaitu $3.313>$ 2.051, dan nilai signifikansi $0,003<0,05$. Dengan demikian ada pengaruh nyata(signifikan) secara parsial dari variabel komitmen (X2) terhadap kepuasan supplier (Y), maka dapat diartikan bahwa hipotesis H1 diterima dan H0 ditolak. Hal ini menunjukkan bahwa supplier sangat puas dengan komitmen yang ditunjukkan oleh perusahaan. Hal tersebut terlihat dari jawaban responden yang sebagian besar responden memberikan jawaban sangat baik (SB) untuk variable komitmen (X2), seperti item "Supplier satu dengan supplier yang lain diperlakukan sama oleh perusahaan" memiliki persentase $70 \%$. Hal tersebut terbukti dengan perusahaan mendapatkan penghargaan kategori pelayan terbaik. Selanjutnya item "Adanya kerjasama yang berkelanjutan" memiliki persentase $67 \%$. Hal tersebut terbukti dari status supplier yang sebagian besar berstatus sebagai supplier tetap dengan rata - rata bekerjasama sebagai supplier Perum BULOG lebih dari 1 tahun atau sudah 2 kali menjadi supplier tetap.

5. Hasil Uji F (Uji Koefisien Regresi Secara Simultan) uji $F$ atau uji simultan dilakukan untuk menguji pengaruh dari semua variable bebas (independen) secara bersamasamaterhadapvariabelterikat

(dependen). Dasar pengambilan keputusan dalam uji F yaitu berdasakan nilai signifikansi dan juga berdasarkan perbandingan $t$ hitung dengan $\mathrm{t}$ tabel. Adapun rumus untuk mencari t table sebagai berikut:

f table

$$
\begin{aligned}
& =\mathrm{f}(\mathrm{k}):(\mathrm{n}-\mathrm{k}) \\
& =(2):(30-2) \\
& =2: 28 \\
& =3,34
\end{aligned}
$$

Keterangan :

$\mathrm{n}=$ jumlah sampel

$\mathrm{k}=$ jumlah variabel $\mathrm{X}$

Tabel 7. Hasil Uji f.

\begin{tabular}{llccccc}
\hline \multicolumn{7}{c}{ ANOVA $^{\mathbf{a}}$} \\
\hline Model & Sum of Squares & Df & Mean Square & F & Sig. \\
\hline 1 & Regression & 75.339 & 2 & 37.669 & $\mathbf{9 . 2 0 2}$ & $\mathbf{. 0 0 1}^{\mathbf{b}}$ \\
& Residual & 110.528 & 27 & 4.094 & & \\
Total & 185.867 & 29 & & & \\
\hline
\end{tabular}

a. Dependent Variabel: Y_kepuasan.

b. Predictors: (Constant), X2_Komitmen, X1_Kepercayaan.

Sumber : Data Primer (Diolah, 2019).

Berdasarkan tabel 7. Diperoleh bahwa nilai F hitung sebesar 9.202 dengan signifikansi 0,001 . Hal tersebut menunjukkan bahwa $\mathrm{F}$ hitung $>\mathrm{F}$ table yaitu $9.202>3.34$, dengan tingkat signifikansi $<0.05$ yaitu 0,001 . Dengan demikian ada pengaruh secara simultan atau secara bersama-sama serta signifikan dari variable kepercayaan (X1) dan komitmen (X2) terhadap variable kepuasaan supplier (Y), maka dapat diartikan bahwa $\mathrm{H} 1$ diterima dan $\mathrm{H} 0$ ditolak. Hal ini menunjukkan bahwa supplier puas dengan kepercayaan dan juga komitmen yang ada diperusahaan Perum BULOG Kantor Cabang Cianjur. $\mathrm{Hal}$ tersebut terlihat dari jawaban responden yang sebagian besar responden memberikan jawaban sangat Puas (SP) untuk variable kepuasan supplier (Y), seperti item "Perum BULOG membantu memberikan solusi atas keluhan supplier" memiliki persentase $70 \%$ dari total $100 \%$, item "Perum BULOG menerapkan sistem pengelolaan kualitas produk terhadap penilaian kualita sberas" dan item "Perjanjian kerja sama dituangkan dalam bentuk tertulis" memiliki 
persentase masing - masing 63\%. Dari jumlah total $100 \%$.

6. Analisis Koefisien Determinasi (R2) Koefisien determinasi dihitung dengan mengkuadratkan koefisien korelasi (R).
Nilai R Square berkisar antara 0 sampai dengan 1, jika nilai R2 sama dengan 0 maka tidak ada sedikitpun persentase sumbangan pengaruh dari variable independen terhadap variable dependen.

Tabel 8. AnalisisDeterminasi (R2).

\begin{tabular}{ccccc}
\hline \multicolumn{5}{c}{ Model Summary } \\
\hline Model & $\mathbf{R}$ & R Square & Adjusted R Square & Std. Error of the Estimate \\
\hline 1 & $.637^{\mathrm{a}}$ & .405 & .361 & 2.023
\end{tabular}

a. Predictors: (Constant), X2_Komitmen, X1_Kepercayaan.

Sumber : Data Primer (Diolah, 2019).

Berdasarkan tabel 8. Diketahui nilai R square sebesar 0,405 atau 40,5\%. Hasil pengujian ini menunjukkan bahwa 40,5\% variable kepuasan supplier dapat dijelaskan oleh variable kepercayaan dan komitmen, sedangkan sisanya 59,5\% dapat dijelaskan oleh variabel lain yang tidak diteliti oleh penulis. Dengan demikian, dapat disimpulkan bahwa variable kepercayaan dan komitmen mempunyai pengaruh terhadap variable kepuasan supplier karena menghasilkan koefisiensi determinasi 40,5\%.

\section{KESIMPULAN}

Berdasarkan hasil analisis data dan juga pembahasan mengenai pengaruh kepercayan dan komitmen terhadap kepuasaan supplier di Perusahaan Umum Badan Urusan Logistik Kantor Cabang Cianjur dapat diambil kesimpulan sebagai berikut :

1. Berdasarkan hasil uji t diperoleh hasil bahwa kepercayaan secara parsial berpengaruh terhadap kepuasan supplier. Hal ini dibuktikan berdasarkan pengujian dengan melihat nilai koefisien $\mathrm{t}$ hitung $>\mathrm{t}$ tabel yaitu $2.532>2.051$ dan nilai sig $<0,05$ pada taraf signifikansi 5\%, maka H1 diterima dan H0 ditolak.

2. Berdasarkan hasil uji t diperoleh hasil bahwa komitmen secara parsial berpengaruh terhadap kepuasan supplier. Hal ini dibuktikan berdasarkan pengujian dengan melihat nilai koefisien $\mathrm{t}$ hitung $>\mathrm{t}$ tabel yaitu
3,313>2.051 dan nilai sig $<0,05$ pada taraf signifikansi 5\%, maka H1 diterima dan $\mathrm{HO}$ ditolak.

3. Berdasarkan hasil uji $f$ atau uji koefisien regresi secara simultan, diperoleh hasil bahwa kepercayan dan komitmen berpengaruh terhadap kepuasan supplier. Hal ini dibuktikan berdasarkan pengujian dengan melihat nilai Fhitung $>$ Ftabel yaitu 9.202>3.34 dan juga nilai sig $<0,05$ pada taraf signifikansi 5\%, maka $\mathrm{H} 1$ diterima dan $\mathrm{HO}$ ditolak.

\section{DAFTAR PUSTAKA}

Ardiansyah, Gumelar. 2019. Pengertian Supplier dan Vendor. http://guruakuntansi.com. Dipost 24 September 2019. (Diakses pada 27 Desember 2019).

Ariani D \& Bambang M.D. 2013. Analisis Pengaruh Supply Chain Management Terhadap Kinerja Perusahaan. (Studi Kasus Pada Industri Kecl dan Menengah Makanan Olahan Khas Padang sumatera Barat). Universitas Diponegoro. Semarang. Jurnal Studi Manajemen \&o Organisasi Vol. 10. No. 2 Juli 2013.

Arif, Muhammad. 2018. Supply Chain Management. Ed.1, Cet. 1. Yogyakarta: CV Budi Utama. (Diakses 30 Desember 2019).

Arikunto, Suharsimi. 2013. Prosedur Penelitian: Suatu Pendekatan Praktik. Cet. 15. Jakarta: Rineka Cipta. 
Bella R. 2019. Tingkat Kepuasan Konsumen Terhadap Beras BULOG di Desa Lawe Rutung Kecamatan Rate Bulan Kutacane. Universitas Muhammadiyah Sumatera Utara. (Diakses pada tanggal 26 Desember 2019).

Burhanudin, Afid. 2013. Analisis Validitas dan Reliabilitas Data. https://afidburhanudin.wordpress, com/2013/05/21/Analisis-

Validitas-dan-Reliabilitas-Data. $\mid$ (Diakses Pada 28 Desember 2019).

Cahyono, Joko. 2010. Faktor -Faktor Yang Mempengaruhi Kerjasama Jangka Panjang Untuk Meningkatkan Keunggulan Kompetitif Perusahaan. Universitas Diponegoro. Semarang. Jurnal. 12 (2): 135-164.

Filiani, Desanti. 2009. Membangun Kepuasan Supplier Dalam Rangka Meningkatkan Kualitas Produksi Perusahaan (Studi Kasus Pada Perusahaan Kayu UD.INDO ARIA Banyu putih Batang). Tesis. Universitas Diponegoro Semarang.

Ghozali, Imam. 2011. Aplikasi Analisis Multivariate Dengan Program IBM SPSS. Semarang: BP Universitas Diponegoro.

Guritno, Adi D \& Meirani Harsasi. 2013. Pengantar Manajemen Rantai Pasok (Supply Chain Management). Edisi ke 2. Yogyakarta: Universitas Terbuka. Online.

Huda, Fatkhan A. 2017. Koefisien Determinasi Pada Regresi Linier. Fatkhan.web,id/koefisiendeterminasi (Diakses Pada 27 Desember 2019).

Hidayat, Anwar. 2012. Uji F dan Uji T-Uji Statistik. https://www.statistikiancom.cdn.a (Diakses Pada 27 Desember 2019).

Kotler, Philip dan Keller. 2009. Manajemen Pemasaran. Jilid 1. Edisike 13. Jakarta: Erlangga.

Mukhsin, Moh. 2017. Pengaruh Kepercayaan Dan Komitmen Terhadap Kualitas Hubungan Dampaknya Pada Kinerja Rantai
Pasok. Universitas Sultan Ageng Tirta yasa Serang_banten. Jurnal manjemen. 21 (03): 454-471.

Nadja A.R, dkk. 2018. Faktor-Faktor Yang Mempengaruhi Kepuasan Pemasok (Supplier) Beras Pada PerumBulog Sub Divre Kota ParePare. Universitas Hasanuddin Makassar. Jurnal Pendidikan Teknologi Pertanian. 4 : S250-S257.

Nuvalentien, Fardana H. 2014. Pengaruh Kepuasan, Kepercayaan, dan Komitmen Terhadap Loyalitas Nasabah Bank Permata di Surabaya. Sekolah Tinggi Ilmu Ekonomi Perbanas Surabaya. Artikel Ilmiah.

Rachman B dan Mohamad Maulana. 2011. Harga Pembelian Pemerintah (HPP) Gabah-Beras Tahun 2010: Efektivitas dan Implikasinya Terhadap Kualitas dan Pengadaan Oleh Dolog. Pusat Sosial Ekonomi dan Kebijakan Pertanian. Analisis Kebijakan Pertanian. 9(4): 331-347.

Raharjo, Sahid. 2016. https://www.spssindonesia.com/2 016/08/cara-cara melakukan uji $\mathrm{F}$ simultan. (Diakses Pada 28 Desember 2019).

Raharjo, Susilo T. 2013. Analisis Kinerja Hubungan Pemasok - Pembeli Studi Hubungan UKM Industri Furnitur Eksportir Furnitur di Jepara. Universitas Diponegoro. (Diakses Pada 20 Januari 2020).

Reza, Iqbal. 2017. Studi Deskriptif Tentang Kinerja Perum Bulog Dalam Pengadaan dan Penyaluran Beras Untuk Mendukung Stabilisasi Pangan. Universitas Erlangga. Jurnal Kebijakan dan Manajemen Publik. 5 (1).

Riduwan. 2015. Dasar-Dasar Statistika. Bandung: Alfabeta.

Sugiyono. 2011. Metode Penelitian Kuantitatif, Kualitatif dan R\& D. Bandung: Alfabeta. 2016. Statistika Untuk Penelitian. Bandung: Alfabeta. 
2016. Metode Penelitian Kuantitatif, Kualitatif dan ReD. Bandung: Alfabeta.

2017. Statistika Untuk Penelitian. Bandung:
Alfabeta. http://www.bulog.co.id/ 2018.

Pengertian Bulog dan Peran Perum

Bulog Dalam Usaha Pengendalian Harga Pangan. (Diakses pada 8 Desember 2019). 